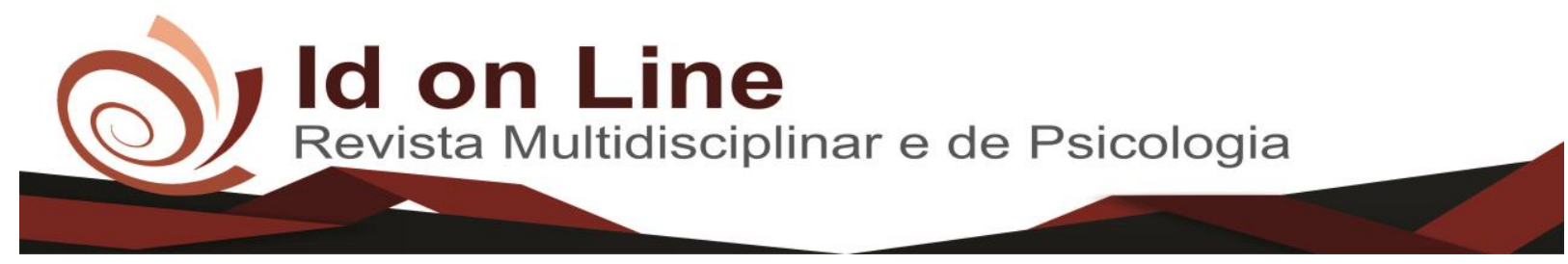

Artigo

\title{
Sustentabilidade na Estratégia como Vantagem Competitiva para as Organizações
}

Josivania Lima Gomes ${ }^{l}$; Adriana Vigolvino Medeiros ${ }^{2}$

Resumo: A responsabilidade socioambiental das organizações é um tema bastante estudado na contemporaneidade e de grande relevância para a sociedade. O consumo exacerbado impacta o meio ambiente devido a uma maior utilização de recursos por parte das empresas para atender as demandas do mercado. Assim, é necessário que as organizações alinhem seus processos produtivos a métodos que sejam menos agressivos à natureza. O objetivo deste artigo é analisar se organizações prestadoras de serviço de utilidade pública, ao trabalhar com responsabilidade social nos processos de gestão estratégica, melhoram sua imagem junto aos consumidores e se estes fatores agregam valor à organização. Foi realizado um estudo de caso em duas empresas, através de entrevista aplicado aos gestores e questionários direcionados aos clientes das empresas. Verificou-se que, embora uma parcela do público pesquisado tenha conhecimento das ações desempenhadas por parte das organizações, falta às empresas pesquisadas melhor alinhamento dos seus propósitos sociais aos processos de planejamento estratégico.

Palavras-Chave: Responsabilidade socioambiental. Gestão estratégica. Competitividade

\section{Sustainability as a Competitive Advantage for the Organizations}

\begin{abstract}
Socio-environmental responsibility of organizations is a subject well studied lately and it is of utmost relevance to society. Exacerbated consumption impacts the environment due as companies use more resources to meet the demands of the market. Thus, it is necessary for organizations to align their productive processes to methods that are less aggressive to nature. The purpose of this article is to analyze whether public service organizations, when working with social responsibility in strategic management processes, improve their image with consumers and if these factors add value to the organization. A case study was carried out in two companies, through an interview applied to managers and questionnaires addressed to the clients of the companies. It was verified that, although a portion of the surveyed public was aware of the actions performed by the organizations, the researched companies should better align their social purposes to the strategic planning processes.
\end{abstract}

Keywords: Social and environmental responsibility. Strategic Management. Competitiveness

\section{Introdução}

Atualmente, a preocupação com o consumo responsável e o compromisso com a responsabilidade social e ambiental nas organizações representa muito mais do que um simples

\footnotetext{
${ }^{1}$ Bacharel em Administração pelo Centro Universitário Dr. Leão Sampaio/UNILEÃO, Juazeiro do Norte-CE, Brasil, josi_lima_@hotmail.com

${ }^{2}$ Professora Orientadora do Centro Universitário Dr. Leão Sampaio/UNILEÃO, Especialista em Planejamento e Gestão Organizacional e Gestão da Qualidade em Serviços pela Universidade Estadual de Pernambuco (UPE) e Mestre em Engenharia de Produção pela Universidade Federal de Pernambuco (UFPE), Juazeiro do Norte-CE, Brasil, adrianamedeiros@leaosampaio.edu.br
} 
modismo: passou a ser parte integrante de uma gestão eficiente, cujas intenções são voltadas para a redução dos impactos ambientais e sociais causados pelas atividades exercidas por parte das empresas. As corporações necessitam trabalhar em prol da população e do planeta. Ser sustentável é um desafio que praticamente todas as organizações almejam, para Valente (2012 apud Scholl; Hourneaux Jr; Galleli, 2016) a sustentabilidade precisa representar uma nova maneira de agir da empresa, não unicamente se basear em práticas voluntárias em resposta às necessidades dos stakeholders, além disso, uma empresa sustentável deve demonstrar a inclusão de aspectos sociais aos seus processos visando sempre a melhoria da relação entre seus processos e o meio social.

Diante da necessidade de se reduzir estes impactos, é imprescindível que a empresa atue de modo responsável perante a sociedade. Isto porque, para a produção de bens ou prestação de serviços, a organização faz uso de recursos naturais, e por consequência participa, ainda que de maneira não intencional, do agravamento do quadro de alterações ambientais. Na visão de Tenório (2006 apud Andrade; Gosling; Jordão, 2013), vários fatores levaram as empresas a se tornarem corporações socialmente responsáveis, de maneira que estes precisam ser vistos de forma conjunta. O primeiro deles foi a falência do bem-estar social, isto é: o meio que antes fluía bem como sociedade começou a apresentar diversos problemas que claramente eram provocados por irresponsabilidades das empresas e bem como de indivíduos.

Tendo em vista que o cenário organizacional descrito acima é composto por ambientes interno e externo, as ações desempenhadas no intuito de agir com responsabilidade socioambiental devem ser alinhadas à estratégia da empresa. Logo, os processos desenvolvidos serão embasados em valores sociais e na ética, cujo tema em questão passa a ser parte integrante da estratégia. Isto é percebido quando Nascimento, Lemos e Mello (2008) afirmam que o termo gestão socioambiental está relacionado às boas práticas desenvolvidas pela empresa, buscando minimizar os impactos negativos e fortalecendo assim sua imagem por toda a cadeia produtiva.

Sendo assim, o objetivo deste artigo é analisar se organizações prestadoras de serviço de utilidade pública, da cidade de Juazeiro do Norte/CE, trabalham com responsabilidade social e ambiental como estratégia e se este processo colabora para sua imagem junto aos consumidores tornando-as mais competitivas. Por meio desta análise foi possível identificar como são desempenhadas as ações e a estratégia destas empresas. Verificou-se que, para que as corporações atinjam seus objetivos e permaneçam no mercado, há necessidade de investirem mais e de maneira mais clara em estratégias de caráter socioambientais. 
Inicialmente foi realizada a descrição da teoria sobre administração estratégica e responsabilidade socioambiental por meio de uma pesquisa bibliográfica. Posteriormente foi realizada uma coleta de dados através de um roteiro de entrevista e um questionário semiestruturado, que serviram de base para uma pesquisa de campo, aplicados na cidade de Juazeiro do Norte- CE, no período de 14 a 16 de outubro de 2017. Para análise dos dados obtidos foi estruturado um estudo de caso. De acordo com Gil (2010, p.37) “(o) estudo de caso consiste no estudo profundo e exaustivo de um ou poucos objetos, de maneira que permita seu amplo e detalhado conhecimento, tarefa praticamente impossível mediante outros delineamentos já considerados". O alvo da exploração foram duas empresas do setor de serviços, designadas empresas A e B. Por fim, após discussão e análise das informações, relacionando-as com a revisão teórica e considerando os aspectos metodológicos, deu-se início as considerações finais.

\section{Gestão Estratégica}

O conceito de gestão estratégica é bem abrangente, e é composto por uma série de ações que envolvem toda a organização. Deste modo, a empresa deixa de ser tratada como um mero instrumento de obter lucros e passa a ter outro significado, abrindo espaço para uma série de ações que farão toda a diferença na sua imagem e trarão vantagem competitiva.

Certo et al. (2005, p. 3) definem administração estratégica como “um processo contínuo e interativo que visa manter uma organização como um conjunto apropriadamente integrado ao seu ambiente". Os autores afirmam tratar de uma série de etapas a ser seguida e repetida, uma etapa cíclica. Assim, toda a empresa se integra ao seu ambiente operacional, frisando que este ambiente sofre constantemente por mudanças, requerendo então que as organizações estejam preparadas para se adequarem a essas transformações.

Completando a afirmativa dos autores supracitada, Harrison (2005) destaca que neste processo, as empresas aprendem por meio das análises internas e externas, assim traçam estratégias que as farão alcançar às metas estabelecidas, e as implementá-las de modo a satisfazer o seu público alvo.

Costa (2007, p. 56) conceitua gestão estratégica “como o processo sistemático, planejado, gerenciado, executado e acompanhado sob a liderança da alta administração da instituição, envolvendo e comprometendo todos os gerentes e colaboradores da organização". 
Segundo ele, trata-se de um processo, cujo objetivo é assegurar o crescimento sustentável da organização, através de estratégias bem delineadas que mudam de acordo com as mudanças externas. A adoção de estratégias baseadas em análises feitas no mercado possibilitará que a organização obtenha vantagem competitiva.

Segundo Chiavenato e Sapiro (2009), a estratégia da empresa está ligada a uma série de hipóteses, onde a melhor será selecionada de acordo com as análises do ambiente organizacional. Seguindo essa linha de raciocínio, o autor afirma que se trata do percurso escolhido pela organização, visando alcançar uma posição futura, melhor do que à atual. Desta maneira a empresa possivelmente apresentará ganhos e vantagens em relação à concorrência. Para ele, quanto mais acuradas forem estas hipóteses, maior será a chance da organização obter êxito na sua estratégia organizacional competitiva.

Hitt, Ireland e Hoskisson (2008, p. 4), referenciam o termo estratégia como um conjunto integrado e coordenado de compromissos e ações para explorar competências essenciais e obter vantagem competitiva.

\section{Processo de Administração Estratégica}

Hitt, Ireland e Hoskisson (2008, p. 6), afirmam que "este processo trata-se de um conjunto completo de compromissos, decisões e ações necessários para que a empresa obtenha vantagem competitiva e retornos acima da média”.

Segundo eles, a organização inicia este processo através da definição da missão, seguida da elaboração de seus objetivos. A próxima fase consiste nas análises interna e externa do ambiente, determinando assim seus recursos, capacitações e competências essenciais. Após analisar o cenário organizacional, a empresa passa para a fase da escolha estratégica que fará com que a empresa obtenha vantagem competitiva. Passadas estas etapas, a empresa dá início a implementação desta estratégia. Os autores enfatizam que este processo é dinâmico, em decorrência das alterações ocorridas constantemente no mercado.

Já para Certo et al. (2005), diferente dos autores acima citados, a sequência deste processo inicia-se pelas análises dos ambientes interno e externo, seguida das definições de missão e objetivos, para que então seja feita a escolha estratégica, implementação e por fim o controle. 
Barney e Hesterly (2011) fortalecem as afirmações dos autores acima citados acerca do modo sequencial em que o processo de administração estratégica ocorre, e ainda completam ao frisarem que a escolha certa aumentará as chances de a organização apresentar vantagem competitiva.

\section{Responsabilidade Social Corporativa}

\section{Evolução Histórica}

As questões sociais vêm sendo largamente discutidas como parte da cultura de uma organização. Todavia, não foi sempre visto desta maneira. Aproximadamente nas três últimas décadas se deu início a preocupação com a produção exacerbada de bens de consumo. Neste contexto, Duarte e Torres (2005) ilustram o modelo fordista como marco inicial de um novo modelo de gestão, cuja preocupação com a produção desenfreada de bens de consumo merece atenção especial. Neste período, uma crise de desemprego impossibilitou o consumo de bens produzidos e apesar dos esforços políticos para vencer este desafio, não obteve êxito desencadeando uma Nova crise econômica.

Por conseguinte, dá-se início a um novo modelo de gestão, cuja preocupação não é mais apenas na grande quantidade de bens produzidos e sim a preocupação de produzir de acordo com a demanda, neste modelo aspectos como contratação, tempo de trabalho e salários eram pontos importantes existentes no modelo. Refere-se ao modelo Toyota de produção. Este processo apresentava-se mais flexível do que o modelo citado anteriormente, cuja característica principal era a produção em larga escala, e os processos ocorriam em linhas de montagem. As autoras afirmam que o advento das novas tecnologias e dos novos processos gerenciais contribuiu fortemente com os impactos sociais.

Duarte e Torres (2005) ilustram o desemprego em decorrência do surgimento de novas funções, que se quer necessitam da intervenção do homem para acontecer. A modernidade resultante dos novos equipamentos fez reduzir de modo considerável o número de colaboradores em alguns setores da economia, pois neste cenário, mão de obra capacitada era escassa. Sendo assim, gerou-se um novo cenário de crise na economia, acarretando uma situação de desemprego e crise econômica. 
Logo depois, surgiu o neoliberalismo no cenário organizacional. Período no qual ocorreram privatizações de empresas estatais, inserção de novos mercados e aumento de produtividade. Esta situação, em vez de proporcionar uma situação mais favorável para a economia, teve ação reversa.

Os autores versam ainda acerca do período dos anos 80, tempos de recessão cujas desigualdades e exclusão social aparecem de maneira expressiva.

Silva (1999 apud DUARTE; TORRES 2005) relata sobre a reforma do estado, ocorrida nos anos 90, onde a esfera estatal assume o papel apenas de mediador e regulador do desenvolvimento econômico e deste modo com a privatização de órgãos públicos a responsabilidade social destas empresas passa a ser de ordem civil. Aumentando, por conseguinte, o grau de parceria entre o estado e estas empresas e havendo o aumento da participação de ONGs (organizações não governamentais) em projetos sociais.

Monteiro (2002 apud DUARTE; TORRES 2005) diz que a sociedade, empresários e governantes buscam soluções para as questões sociais, e que estas são resultantes da omissão de algumas políticas públicas.

\section{Conceito e Importância}

Segundo Borger (2006), responsabilidade social não é um conceito fácil, visto que as questões éticas, ambientais e sociais são complicadas e mutáveis. Trata-se de um conjunto de atividades, trabalhadas de modo sistêmico, e que mobilizam todos os envolvidos a alcançarem as metas e objetivos traçados de maneira ética, gerando melhoria para a sociedade e ambiente no qual ela estar inserida.

Já Wright, Kroll e Parnell (2011), fazem menção às questões sociais como ações que gerem benefícios para todos os envolvidos no processo produtivo, e enfatizam o fato destas questões irem além da simples satisfação dos clientes com a oferta de bens ou serviços. Segundo os autores devido às empresas fazerem parte da sociedade, torna-se impossível isolar suas ações, pois para eles quaisquer decisões tomadas por parte da organização trarão reflexos financeiros e sociais. 
“A responsabilidade social, é convergente com estratégias de sustentabilidade à longo prazo, inclui a necessária preocupação dos efeitos das atividades desenvolvidas no contexto da comunidade em que se inserem as empresas [...]" (TINOCO, 2001 apud TACHIZAWA 2005, p. 87).

Ao abordar o tema Zarpelon (2006), alerta que responsabilidade social e responsabilidade ambiental têm conceitos distintos onde a social refere-se às pessoas e onde elas estão inseridas, enquanto que a ambiental prioriza o meio ambiente, estando relacionada a fatores bióticos e abióticos. Para o autor, a responsabilidade social está relacionada ao atendimento dos interesses coletivos.

Kraemer (2005 apud Lima 2009) reforça as afirmativas anteriores e completa, quando cita que se trata de um conceito que abrange muitas responsabilidades, que a empresa adota em relação aos envolvidos no cenário organizacional, cuja empresa responsável vai além das obrigações exigidas por lei. Ele afirma que a empresa ao adotar esta metodologia, tem uma visão de que agindo deste modo contribuirá para a redução das desigualdades sociais.

\footnotetext{
A responsabilidade da empresa se justifica pela qualidade de comprometimento com pessoas, comunidades, sociedade e meio ambiente, uma vez que os impactos e as influências atingem diretamente toda a cadeia de relacionamento, interferindo propositalmente na satisfação de necessidades básicas e de sobrevivência, refletindo no processo de mudança social (LIMA 2009, p. 122-123).
}

Chiavenato e Sapiro (2009) exaltam que para sobreviver neste mercado atual, é imprescindível que os empresários adotem uma postura responsável junto aos clientes, colaboradores, acionistas, comunidade e seu ambiente, e completa dizendo que uma organização é considerada responsável quando segue as obrigações descritas a seguir:

- Alinha seus propósitos sociais aos processos de planejamento estratégico;

- Realizam nos seus programas sociais, regras de comparação com outras organizações;

- Trabalha com transparência com seus colaboradores e parceiros, utilizando-se de relatórios para deixá-los informados de como progride na responsabilidade social;

- Faz uso de várias maneiras para medir seu desempenho social;

- Avalia custos e retornos sobre investimentos, no que é gasto com programas sociais.

De acordo com Melo Neto e Froes (2001), a responsabilidade social pode ocorrer interna e externamente. Onde internamente, a empresa buscará motivar seu quadro funcional, de modo 
que propicie um ambiente de trabalho agradável, e assim, certamente refletirá positivamente nos resultados organizacionais. Visto que, o colaborador motivado, procura fazer bem feito, uma vez que ele se sente parte integrante da corporação. A responsabilidade social interna proporcionará não apenas boas condições de trabalho, mas um local onde o profissional se sentirá realizado.

Já no ambiente externo os autores citados anteriormente, dizem que a organização visará promover o bem-estar social da comunidade na qual está inserida. Eles afirmam que o foco está na comunidade, através de ações sociais voltadas, principalmente, para as áreas de educação, saúde, assistência social e ecologia. Visa um maior retorno social, de imagem, publicitário e para os acionistas. Todavia, ação social e responsabilidade social são conceitos distintos que não dever ser confundidos.

\section{Gestão Socioambiental e Estratégia Competitiva}

Nascimento, Lemos e Mello (2008), afirmam que o termo gestão socioambiental está relacionado às boas práticas desenvolvidas pela empresa, onde buscam minimizar os impactos negativos fortalecendo assim, sua imagem por toda a sua cadeia produtiva. Os autores conceituam este tipo de gestão, como o ato de adotar uma nova metodologia nos seus processos gerenciais, agregando o fator socioambiental à sua estratégia. Sublinham o fato de a organização agir com transparência, alinhando os seus objetivos a essa nova cultura, e que à longo prazo, haverá maior probabilidade de que os consumidores ao buscarem por determinado produto optem por aquele, cuja empresa demonstra comprometimento e respeitabilidade.

Valle (2004), relata que uma empresa tem responsabilidade social e ambiental, quando adota práticas socialmente responsáveis. E exalta que ao unirem seus processos às questões ambiental e ecológica, apresentarão significativa vantagem competitiva, com reflexos positivos nos seus lucros.

Conforme o Instituto Ethos (2013), o avanço por parte da iniciativa privada em preservar os recursos naturais, além de gerar benefícios para a sociedade e para as gerações futuras, também reflete na lucratividade da empresa. Também enfatiza que o modo como o qual a produção de bens e o consumo se dão, é fator preponderante para que existam problemas social e ambiental. 
Já a revista Confenar (2009), versa sobre responsabilidade socioambiental associandoa ao tripé: pessoas, planeta e lucro. A matéria faz menção às empresas que promovem ações que envolvem a preocupação com a responsabilidade no ambiente ao qual está inserida, vislumbrando a obtenção de lucros. Diz ainda que as organizações devem agir com clareza acerca das ações desenvolvidas por elas. Deixando claro que esta conduta trará resultados positivos para a empresa, melhorando sua imagem, e trará benefícios para o relacionamento entre os que compõem a cadeia produtiva.

Ainda no artigo supracitado, há ilustração da sequência de como se devem implantar as ações sustentáveis nas empresas. A princípio é importante que o gestor se engaje na causa, e adote as práticas sustentáveis. O próximo passo consiste no estabelecimento de uma política ambiental, juntamente com o RH. Logo mais, ressalta-se a importância do não envolvimento da organização em trabalhos que explorem a mão de obra infantil ou até mesmo o trabalho escravo. E por fim, agir de acordo com a política ambiental e disseminar esta cultura entre os colaboradores.

\section{Procedimentos Metodológicos}

Este trabalho teve como base a pesquisa bibliográfica, pesquisa que, de acordo com Cervo e Bervian (2002), parte de referências teóricas já publicadas para formar novos conhecimentos. Também foram consultados sites e revistas que contêm informações acerca do tema abordado.

A técnica usada foi o estudo de caso, pois de acordo com Gil (2010, p.37) "estudo de caso consiste no estudo profundo e exaustivo de um ou poucos objetos, de maneira que permita seu amplo e detalhado conhecimento, tarefa praticamente impossível mediante outros delineamentos já considerados”. Realizou-se então o estudo de caso em duas empresas do setor de serviços onde as mesmas serão apresentadas nesta presente pesquisa como empresa A e empresa B.

A empresa A é uma organização de grande porte, ofertante de serviços para toda a população, pois há apenas ela atuando no seu setor em todo o estado do Ceará, sendo 2 núcleos nesta cidade, com 250 funcionários que atuam no Juazeiro. 
A empresa B também é uma organização de grande porte, porém estar presente em todo o Ceará, sendo que 263 localidades são beneficiadas com a prestação de seus serviços. Já com sistema de esgotamento sanitário, a Companhia atende 72 cidades cearenses. Possui 4 núcleos de atendimento nesta cidade e conta com 350 funcionários atuantes em Juazeiro do Norte-CE.

Para a coleta de dados, utilizou-se dois instrumentos: uma entrevista semiestruturada e um questionário estruturado. A entrevista semiestruturada, composta por perguntas subjetivas, foi realizada com os gestores da área socioambiental de 2 empresas prestadoras de serviço de utilidade pública. Já o questionário, com 4 questões objetivas, foi utilizado para coleta de dados junto a 50 pessoas que compõem o público consumidor das empresas em estudo. Teve como objetivo colher informações relevantes acerca da percepção dos consumidores com relação às ações de natureza socioambiental que as empresas julgam desempenhar para confrontá-las com as ações da empresa, tanto do ponto de vista dos gestores, quanto da teoria em vigor sobre o assunto .

Ambos os instrumentos serviram de base para uma pesquisa de campo, aplicados na cidade de Juazeiro do Norte- CE, no período de 14 a 16 de outubro de 2017. A pesquisa possui natureza qualitativa, pois nela há o levantamento e experimentação, características citadas por Ludwing (2012), passando posteriormente a assumir caráter descritivo. De acordo com Gil (2010) os dados são primários, cujo conteúdo foi recolhido por entrevistas e questionários semiestruturados e estruturados.

\section{Resultados}

\section{Entrevista com os Gestores}

$\mathrm{Na}$ descrição dos resultados as empresas entrevistadas foram denominadas empresa A e empresa B. Para análise dos dados a entrevista foi dividida em três tópicos macros: à importância dos impactos socioambientais causados pela prestação de seus serviços, a posição estratégica nas empresas da responsabilidade socioambiental e a importância do fator socioambiental nos processos gerenciais das organizações. A cada tema abordado foi realizada uma análise de acordo com o objetivo proposto no trabalho. 
O primeiro ponto tratado na entrevista foi à importância dos impactos socioambientais causados pela prestação de seus serviços.

Observou-se que a empresa A está mais integrada ao modelo de gestão que considera a responsabilidade socioambiental, pois o entrevistado, além de falar de maneira ampla sobre o assunto, dispôs ao pesquisador um rico material que torna possível o conhecimento das ações que são desempenhadas por ela. Ações estas que vão além da preocupação com os reflexos de suas atividades produtivas. Por outro lado, na empresa B, embora tenha sido afirmado existir uma política socioambiental na empresa, possui poucas ações que envolvem a comunidade neste sentido.

Algo relevante a ser descrito é o fato de que ambas as instituições dispõem de um gestor responsável por conduzir as ações que envolvem as questões socioambientais.

O segundo assunto abordado tratou da posição estratégica da responsabilidade socioambiental nas empresas.

O gestor da empresa A, responsável pela gestão socioambiental de toda empresa, informou que frequentemente há reuniões de planejamento estratégico contendo o fator socioambiental na pauta. Da mesma maneira a empresa B possui um gestor responsável pelos assuntos socioambientais. Porém, diferente da empresa A, há em cada unidade de negócio um responsável. Ressalta-se que a empresa B possui 33 núcleos de atendimento no interior do Ceará sendo 4 unidades em Juazeiro.

Os entrevistados, também foram questionados a respeito do alinhamento dos seus processos produtivos à política de preservação ambiental. Na empresa $\mathrm{A}$, a redução de consumo de energia e ações que promovam o bem estar social são temas recorrentes nas reuniões da alta gerência, onde são estabelecidos metas e objetivos, alinhados a este modelo de gestão. Também são estabelecidos indicadores sociais como meio de se medir a eficácia de suas ações.

Quanto à empresa B, o gestor afirma que a base do seu planejamento estratégico é a questão ambiental e que todos os seus produtos e subprodutos passam por estudos para se averiguarem quais são os impactos decorrentes de suas atividades. Isto demonstra um alinhamento entre a gestão socioambiental e a gestão estratégica da empresa.

Outro dado analisado foi a importância do fator socioambiental nos processos gerenciais das organizações. Com relação a este tema, a empresa A procura capacitar seus colaboradores de modo que estes ofereçam um serviço de qualidade, criando assim, valor para sua marca, com a finalidade de ser uma empresa modelo. De acordo com o gestor da empresa A, há retornos 
financeiros em decorrência de ações socioambientais, pois em virtude delas, há redução de custos produtivos e também há um trabalho de destinação correta de seus resíduos.

A empresa A possui um manual informativo, cuja função é informar como os colaboradores devem atuar com relação às práticas socioambientais. Aos egressos na organização é oferecido treinamento, e mensalmente há reunião entre os gestores desta área para fins de acompanhamento e conhecimento se haverá alguma mudança na sua forma de atuação.

Junto à comunidade a empresa mantém um programa de troca de materiais recicláveis por créditos na sua conta, podendo muitas vezes esta conta vir a zerar, afirma ele.

A este respeito à empresa $\mathrm{B}$ ressalta a constante busca pela melhoria de seus processos, e o engajamento de seus profissionais através de capacitação. Para a empresa B, o preço cobrado ao consumidor tem grande importância, pois trabalha a questão social, visto que é uma empresa sem concorrente direto no mercado em que atua. Ela tem uma das menores tarifas do Brasil, estando no ranking da terceira menor tarifa aplicada no Brasil cobrado à população. Há divulgação da qualidade e preço nas faturas, assim todos podem ter acesso a estes dados.

Por parte da empresa $\mathrm{B}$, ilustra-se o tratamento da água e ações voltadas à conscientização da preservação ambiental realizadas em escolas e na própria instituição. Além destas práticas, realiza eventos mensais e internos para acompanhamento de como os colaboradores estão atuando com relação às questões socioambientais.

\section{Aplicação de Questionário aos Clientes}

Para entender se as boas práticas listadas pelas empresas entrevistadas, relacionadas à gestão socioambiental, são percebidas e reconhecidas pelos consumidores, foram feitas as seguintes perguntas: fatores de relevância para utilização dos serviços, conhecimento das ações socioambientais desempenhadas pelas empresas, sugestões dos clientes para atuação sustentável das empresas, motivação das empresas em adotar ações socioambientais. Segue descrição e análise dos resultados. O gráfico 1, ilustra qual a motivação dos clientes ao optarem por determinado produto/ serviço. 
Gráfico 1- Quais dos fatores abaixo são relevantes para utilização dos serviços? (número absoluto)

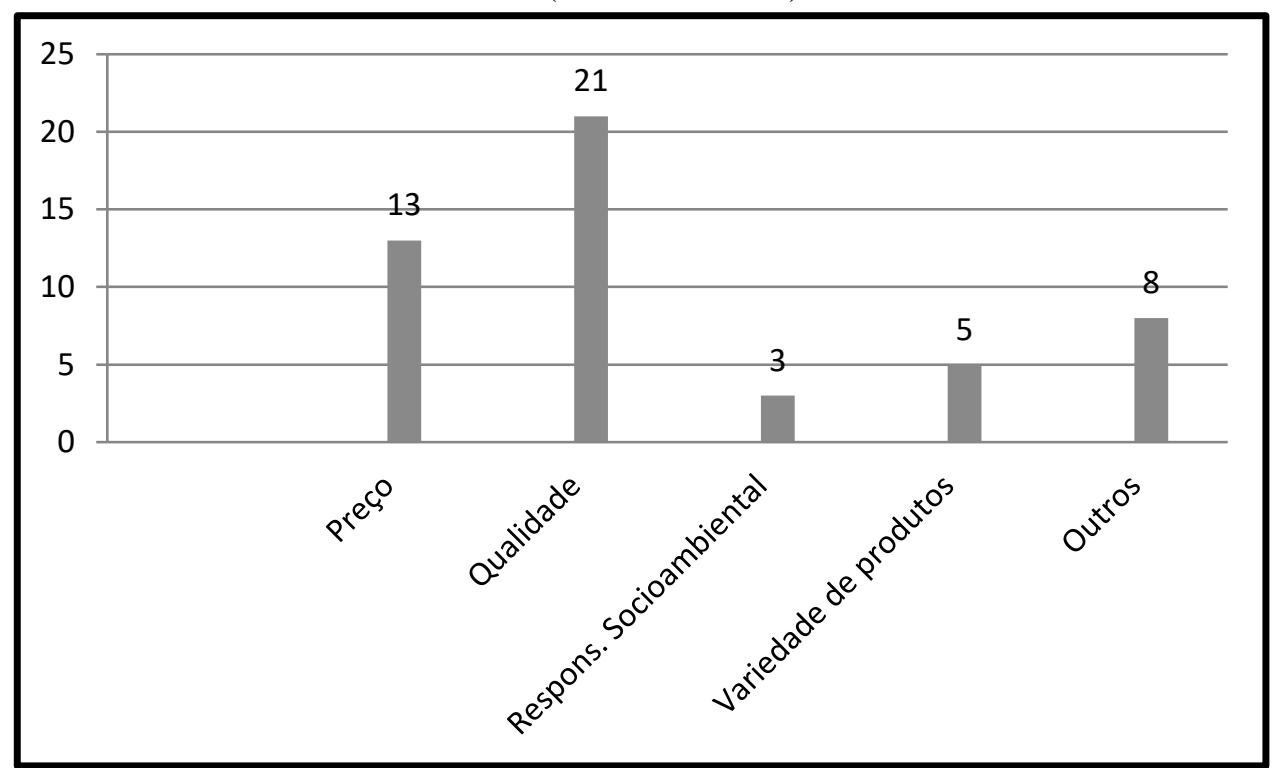

Fonte: Dados da pesquisa (2017)

De acordo com os dados apresentados no Gráfico 1, apenas 3 dos 50 entrevistados afirmaram que a responsabilidade socioambiental é um fator de relevância na escolha dos serviços, o que corresponde a $6 \%$ da amostra. Um valor insignificante que demonstra a despreocupação com a preservação ambiental.

Também foi indagado se estes consumidores conheciam as ações socioambientais desempenhadas pelas empresas A e B. A pergunta foi formulada de modo que os clientes julgassem as empresas de maneira dissociada. Assim 75\% dos respondentes afirmaram conhecer as ações socioambientais da empresa A, enquanto que $25 \%$ afirmaram não ter conhecimento. Sobre a empresa B 35\% dos entrevistados afirmaram conhecer as medidas socioambientais da empresa, enquanto $65 \%$ responderam desconhecer tais práticas.

O Gráfico 2 ilustra que medidas estes clientes julgam necessárias para que as empresas exerçam de fato a responsabilidade socioambiental. Os dados do Gráfico 2 são números absolutos de respondentes. 
Gráfico 2- Das ações abaixo, qual seria a sua sugestão para empresa atuar com mais responsabilidade socioambiental?

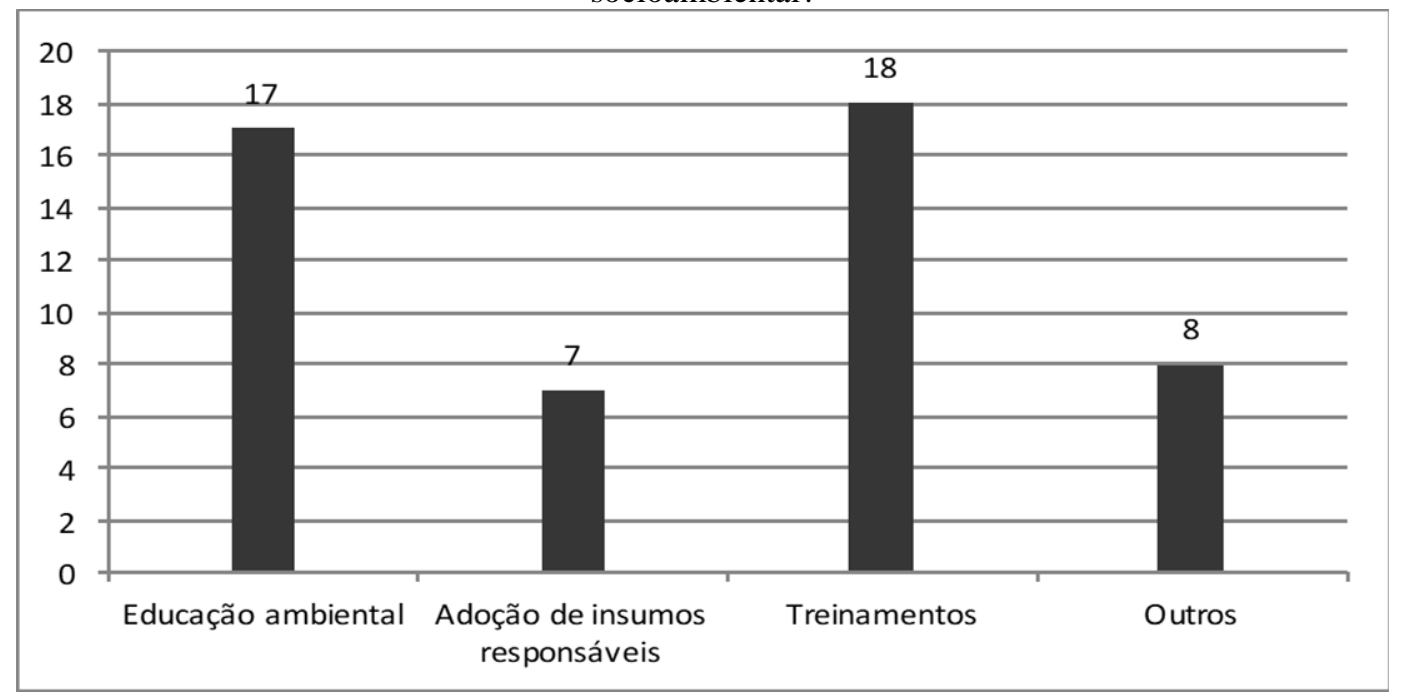

Fonte: Dados da pesquisa (2017)

De acordo com o Gráfico 2 vê-se que $34 \%$ e $36 \%$ dos pesquisados acreditam que educação e treinamento, respectivamente, são fatores preponderantes para que as empresas atuem efetivamente na política socioambiental.

No Gráfico 2, os clientes julgaram o fator educação junto à população e a capacitação do grupo de colaboradores das empresas, como fatores indissociáveis para que a organização cumpra seu papel junto à sociedade de modo satisfatório.

Com relação a cadeia de valor, ou seja, ao questionamento sobre insumos responsáveis, $14 \%$ dos entrevistados, informaram ter conhecimento dos processos adotados para aquisição de produtos e serviços por parte das empresas. O Gráfico 3 mostra as opiniões expressadas pelos clientes. 
Gráfico 3- Qual a principal motivação das empresas ao adotarem ações socioambientais

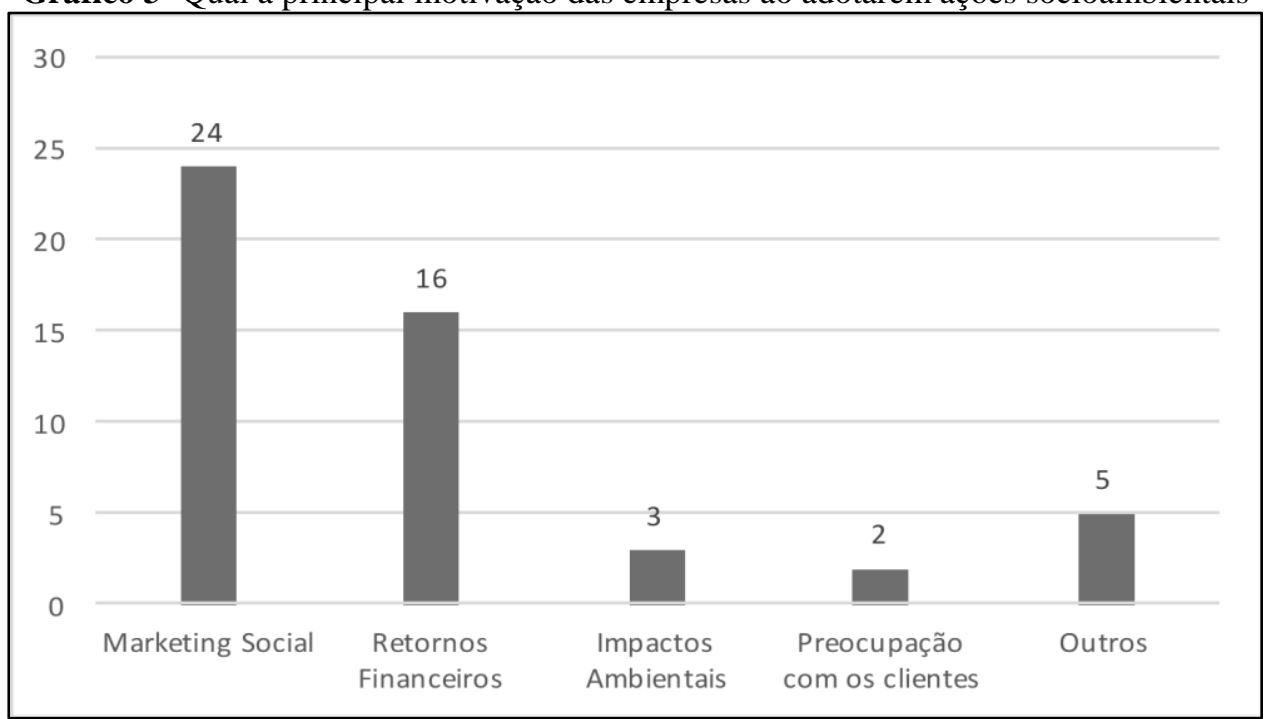

Fonte: Dados da pesquisa (2017)

De acordo com o Gráfico 3 pode-se inferir que a maioria dos entrevistados julgam o marketing social e possíveis retornos financeiros como motivos pelos quais as empresas adotam posturas sustentáveis e responsáveis representando $48 \%$ e $32 \%$ da amostra, respectivamente.

Ao serem questionados em relação aos serviços prestados pelas empresas em questão, os resultados foram mais favoráveis à empresa $\mathrm{A}$, que demonstrou significativo resultado positivo em relação à empresa B. Os resultados são apresentados no gráfico 4.

Gráfico 4- Satisfação do cliente com os serviços prestados

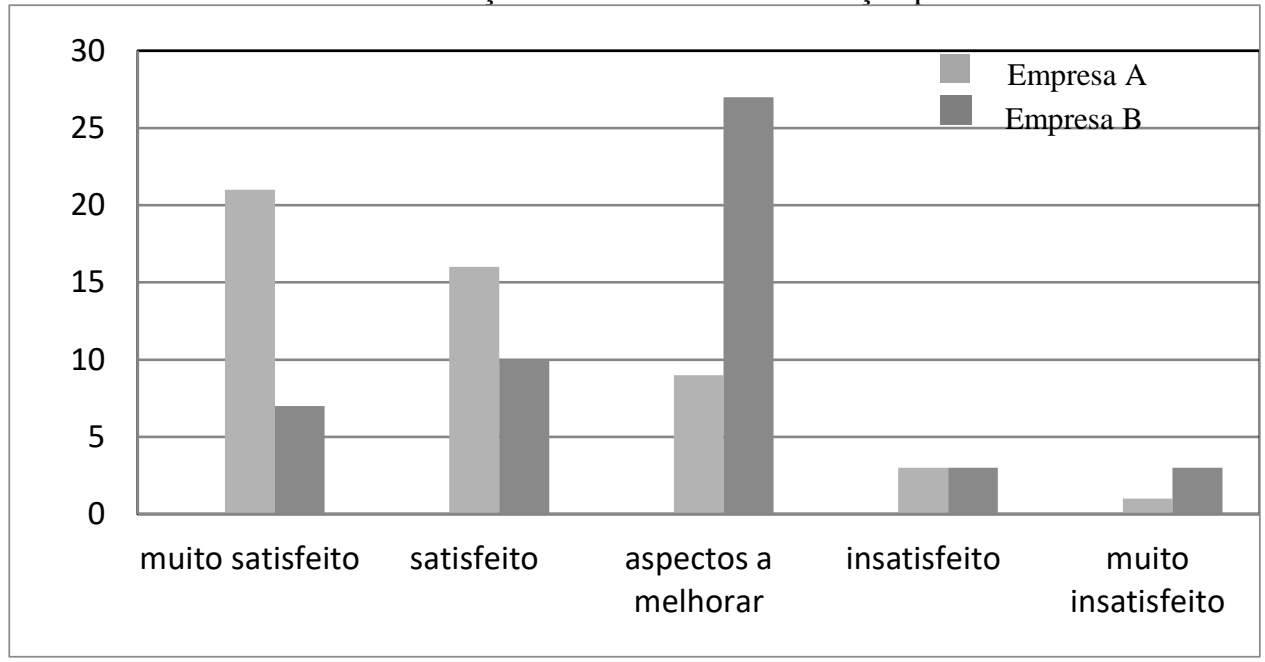

Fonte: Dados da pesquisa (2017) 
O Gráfico 4 demonstra o quão satisfeito está o público consumidor em relação ao serviço prestado pelas empresas. Neste quesito, $42 \%$ dos consumidores sentem-se muito satisfeitos com o serviço da empresa A, 32\% satisfeitos e $18 \%$ julgam que a empresa precisa melhorar o seu serviço. No mesmo contexto $14 \%$ do público da empresa B apresentaram- se muito satisfeitos com o serviço, $20 \%$ estão satisfeitos e $54 \%$ acreditam que a empresa B deve melhorar o atendimento.

\section{Discussão}

Esta seção tem como objetivo fazer uma breve descrição da correlação entre a teoria e os dados obtidos na pesquisa. Os quadros 1 e 2 - diferenças das percepções entre clientes e gestores, mostra um resumo dos itens que foram avaliados.

Quadro 1 - diferenças das percepções entre clientes e gestores

\begin{tabular}{|c|c|c|c|}
\hline Item & Respondentes & Pergunta & Percepção \\
\hline \multirow[b]{2}{*}{1} & Cliente & $\begin{array}{l}\text { Fatores relevantes para } \\
\text { utilização dos serviços }\end{array}$ & $\begin{array}{l}\text { Pouca Importância: O cliente não entende, } \\
\text { as questões ambientais como um fator } \\
\text { relevante }\end{array}$ \\
\hline & Gestor & $\begin{array}{l}\text { Importância dos impactos } \\
\text { socioambientais causados } \\
\text { pela prestação de seus } \\
\text { serviços }\end{array}$ & $\begin{array}{c}\text { EMPRESA A: } \\
\text { Importância alta. Demonstra evidências de } \\
\text { efetiva implementação de ações } \\
\text { socioambientais. } \\
\text { EMPRESA B: } \\
\text { Pouca importância. Afirma existir uma } \\
\text { política socioambiental na empresa, mas } \\
\text { possui poucas ações neste sentido. }\end{array}$ \\
\hline \multicolumn{2}{|c|}{$\begin{array}{l}\text { Análise cruzada de } \\
\text { dados }\end{array}$} & \multicolumn{2}{|c|}{$\begin{array}{l}\text { Mesmo com ações implementadas, na visão dos gestores, a estratégia só é } \\
\text { percebida pelos stakeholders internos. Todo o esforço interno não consegue } \\
\text { se transformar em diferencial estratégico com relação ao mercado. }\end{array}$} \\
\hline \multirow[b]{2}{*}{2} & Cliente & $\begin{array}{l}\text { Sugestão para empresa atuar } \\
\text { com mais responsabilidade } \\
\text { socioambiental }\end{array}$ & $\begin{array}{l}\text { Pouca Importância: O cliente ainda sente } \\
\text { necessidade de ações voltadas para educação } \\
\text { ambiental e capacitação dos colaboradores } \\
\text { neste aspecto }\end{array}$ \\
\hline & Gestor & $\begin{array}{l}\text { Posição estratégica da } \\
\text { responsabilidade } \\
\text { socioambiental nas empresas. }\end{array}$ & $\begin{array}{c}\text { EMPRESA A: } \\
\text { Importância alta. Inclui na pauta de } \\
\text { planejamento estratégico a responsabilidade } \\
\text { socioambiental, além de possuir um setor } \\
\text { para fazer a gestão desta área } \\
\text { EMPRESA B: } \\
\text { Importância alta. Afirma existir uma área } \\
\text { especifica e responsáveis de nível } \\
\text { estratégico e tático. }\end{array}$ \\
\hline
\end{tabular}




\begin{tabular}{|c|c|}
\hline $\begin{array}{c}\text { Análise cruzada de } \\
\text { dados }\end{array}$ & $\begin{array}{c}\text { O mercado ainda não percebe as questões socioambientais como parte da } \\
\text { cultura das empresas, por isto sugerem mais investimentos em educação para } \\
\text { comunidade. Ou seja: toda a pauta de planejamento estratégico e } \\
\text { responsáveis por estas questões nas organizações não são suficientes para a } \\
\text { percepção do público externo }\end{array}$ \\
\hline
\end{tabular}

Fonte: Dados da pesquisa (2017)

Avaliando o item 1 nota-se que, mesmo com ações de natureza socioambientais, a estratégia só é percebida pelos stakeholders internos. Todo o esforço interno não consegue se transformar em diferencial estratégico com relação ao mercado, Chiavenato e Sapiro (2009) relatam que para sobreviver no mercado atual, é imprescindível que os empresários adotem uma postura responsável junto aos clientes, colaboradores, acionistas, comunidade e seu ambiente, e completa dizendo que uma organização é considerada responsável quando alinha seus propósitos sociais aos processos de planejamento estratégico. Nos dados pesquisados os objetivos sociais das empresas não são vistos pelo mercado como parte integrante da estratégia organizacional.

Já no item 2, o fator educação ambiental, também tem apenas reflexos internos e segundo Tinoco (2001 apud TACHIZAWA 2005), a responsabilidade social, precisa está convergindo com as estratégias de sustentabilidade à longo prazo. Isto inclui a necessária preocupação dos efeitos das atividades desenvolvidas no contexto da comunidade em que se inserem as empresas.

Quadro 2 - diferenças das percepções entre clientes e gestores

\begin{tabular}{|c|c|c|c|}
\hline Item & Respondentes & Pergunta & Percepção \\
\hline \multirow[b]{2}{*}{3} & Cliente & $\begin{array}{l}\text { Principal motivação das } \\
\text { empresas ao adotarem ações } \\
\text { socioambientais }\end{array}$ & $\begin{array}{l}\text { Pouca Importância: a maioria dos } \\
\text { entrevistados julgam marketing social como } \\
\text { principal motivação }\end{array}$ \\
\hline & Gestor & $\begin{array}{l}\text { Alinhamento dos seus } \\
\text { processos produtivos à } \\
\text { política de preservação } \\
\text { ambiental }\end{array}$ & $\begin{array}{c}\text { EMPRESA A: } \\
\text { ações de bem estar social são temas } \\
\text { recorrentes nas reuniões da alta gerência, } \\
\text { estabelecidos metas e objetivos como meio } \\
\text { de se medir a eficácia de suas ações. } \\
\text { EMPRESA B: } \\
\text { todos os seus produtos e subprodutos passam } \\
\text { por estudos para se averiguar quais são os } \\
\text { impactos decorrentes de suas atividades }\end{array}$ \\
\hline \multicolumn{2}{|c|}{$\begin{array}{c}\text { Análise cruzada de } \\
\text { dados }\end{array}$} & \multicolumn{2}{|c|}{$\begin{array}{c}\text { As operações internas das organizações tem em suas estratégias a visão de } \\
\text { processos produtivos mais limpos, no entanto, os clientes não entendem isto } \\
\text { de forma positiva, mas apenas como uma forma de obter mais lucro através } \\
\text { do marketing social. }\end{array}$} \\
\hline
\end{tabular}




\begin{tabular}{|c|c|c|c|}
\hline \multirow[b]{2}{*}{4} & Cliente & $\begin{array}{l}\text { Satisfação do cliente com os } \\
\text { serviços prestados }\end{array}$ & $\begin{array}{l}\text { Pouca Importância: Apenas na empresa A as } \\
\text { ações socioambientais são percebidas pelo } \\
\text { público como fator de satisfação do cliente }\end{array}$ \\
\hline & Gestor & $\begin{array}{l}\text { Importância do fator } \\
\text { socioambiental nos processos } \\
\text { gerenciais das organizações }\end{array}$ & $\begin{array}{c}\text { EMPRESA A: } \\
\text { Importância alta. Investe em processos } \\
\text { internos de modo que a ter serviço de } \\
\text { qualidade, criando assim, valor para sua } \\
\text { marca. } \\
\text { EMPRESA B: } \\
\text { Importância alta: Ressalta a constante busca } \\
\text { pela melhoria de seus processos como forma } \\
\text { de redução do preço para o cliente. }\end{array}$ \\
\hline \multicolumn{2}{|c|}{$\begin{array}{l}\text { Análise cruzada de } \\
\text { dados }\end{array}$} & \multicolumn{2}{|c|}{$\begin{array}{l}\text { Pode-se perceber que, embora ambas empresas pesquisadas procurem atuar } \\
\text { de modo responsável, não há percepção por parte dos clientes da empresa B } \\
\text { desta política de gestão socioambiental. }\end{array}$} \\
\hline
\end{tabular}

Fonte: Dados da pesquisa (2017)

O item 3, exposto no Quadro 2, trata tanto da motivação socioambiental das empresas sob a ótica dos clientes, como da percepção dos gestores com relação aos processos produtivos. Percebe-se que os clientes presumem que todo o investimento da organização em processos produtivos mais limpos é apenas uma ação voltada para a publicidade, o marketing social, e não como um fator de preocupação efetiva das organizações em ter isto como estratégia. De acordo com Hitt, Ireland e Hoskisson (2008), o termo estratégia como um conjunto integrado e coordenado de compromissos e ações para explorar competências essenciais e obter vantagem competitiva. Nas empresas pesquisadas a estratégia se dá apenas no âmbito organizacional interno e não se reflete como vantagem competitiva para o mercado.

Também no Quadro 2, item 4, avaliando a satisfação do cliente com relação a execução dos processos internos, pode-se observar que embora as empresas pesquisadas procurem atuar de modo responsável, não há percepção por parte dos clientes desta política de gestão socioambiental. A qualidade interna dos processos ainda não se caracteriza como fator de confiabilidade e satisfação para os clientes. A este respeito, pode-se trazer o que Certo et al. (2005, p. 3) definem como administração estratégica "um processo contínuo e interativo que visa manter uma organização como um conjunto apropriadamente integrado ao seu ambiente". O que não acontece nas organizações pesquisadas em virtude das percepção do cliente com relação a satisfação e qualidade interna e externa dos processos. 


\section{Considerações Finais}

Foi observado que, embora o fator socioambiental seja de grande importância, para a sobrevivência das organizações e bem-estar da sociedade, ainda não é fator de influência na aquisição de bens/serviços. Segundo Lima (2009), a responsabilidade da empresa se justifica pela qualidade de comprometimento com pessoas, comunidades, sociedade e meio ambiente, uma vez que os impactos e as influências atingem diretamente toda a cadeia de relacionamento, interferindo na satisfação de necessidades básicas e de sobrevivência, refletindo no processo de mudança social. Ou seja: mesmo que as empresas possuam política de gestão socioambiental, não é suficiente se não houver conhecimento por parte dos clientes. Esta forma de gestão deve abranger todos os envolvidos no processo produtivo, todo o ciclo deve receber atenção por parte dos gestores.

Assumindo esta postura, certamente haverá retornos positivos tanto para a organização, quanto para o público consumidor. Isto pode ser implementado adotando-se o um processo de administração, que segundo Barney e Hesterly (2011) devem contemplar a missão, visão e os valores da organização, de forma sequencial, e ainda frisam que a escolha certa destes elementos aumentará as chances de a organização apresentar vantagem competitiva. O que expressa a importância das questões socioambientais presentes na empresa desde do início do processo de elaboração da estratégia. Percebe-se que o fator socioambiental ainda têm questões a serem exploradas de modo amplo, devendo haver um envolvimento entre empresa e público, visto que ambos estão inseridos no mesmo ambiente.

A percepção dos clientes em relação às práticas socioambientais desempenhadas pelas organizações estudadas é a de que a empresa busca se promover, melhorando seu marketing social ou obtendo lucros, e não há preocupação com os impactos ambientais e seus reflexos junto a população. Assim, conclui-se através deste trabalho a suma importância de levar ao conhecimento dos consumidores as ações tomadas pelas empresas em âmbito social e ambiental, para que tais práticas se tornem efetivamente uma estratégia organizacional e sejam disseminadas em toda a sociedade. 


\section{Referências}

ANDRADE, M. A. M.; GOSLING, M.; JORDÃO, R. V. D.: Responsabilidade social de siderúrgicas mineiras e a percepção de suas comunidades de entorno. Produção. v. 23, n. 4, p. 793-805, out./dez. $2013 . \quad$ Disponível em: <http://www.scielo.br/pdf/prod/v23n4/aop_t6_0007_0709.pdf >. Acesso em: 14 set.2016.

BARNEY, Jay B.; HESTERLY, Willian S. Administração Estratégica e Vantagem Competitiva: Conceitos e Casos. 3 ed. São Paulo: Pearson Prentice Hall, 2011.

BORGER, Fernanda Gabriela. Responsabilidade corporativa: a dimensão ética, social e ambiental na gestão das organizações. In: VILELA JUNIOR, Alcir; DEMAJOROVIC, Jacques. (org.). Modelos e ferramentas de gestão ambiental: Desafios e perspectivas para as organizações. São Paulo: Senac, 2006.

COSTA, Eliezer Arantes da. Gestão Estratégica: da empresa que temos a empresa que queremos. 2. ed. São Paulo: Saraiva, 2007.

CERTO, Samuel C.; PETER, J. Paul; MARCONDES, Reynaldo Cavalheiro; CESAR, Ana Maria Roux. Administração estratégica: planejamento e implantação da estratégia. 2. Ed. São Paulo: Pearson Prentice Hall, 2005.

CERVO, Amado Luíz; BERVIAN, Pedro Alcino. Metodologia Científica. 5 ed. São Paulo: Pearson Prentice Hall, 2002.

CHIAVENATO, Idalberto; SAPIRO, Arão. Planejamento estratégico: Fundamentos e aplicações. 2 ed. Rio de Janeiro: Elsevier, 2009.

CONFENAR. Sustentabilidade na prática. Rev. Confenar. 29. Ed. a. 5.jul. 2009.

DUARTE, Cristiane de Oliveira Silva; TORRES, Juliana de Queiroz Ribeiro. Responsabilidade Social das Empresas: A contribuição das universidades. 4 ed. São Paulo: Peirópolis: Instituto Ethos, 2005.

ETHOS. 2013. Disponível em: <http://www3.ethos.org.br/conteudo/gestao-socialmenteresponsavel/meio-ambiente/\#.Vbjevfegtrx>. Acesso em: 16 ago. 2014.

GIL, Antônio Carlos. Como elaborar projetos de pesquisa. 5. ed. São Paulo: Atlas, 2010.

HARRISON, Jeffrey S. Administração estratégica de recursos e relacionamentos. Porto Alegre: Bookman, 2005.

HITT, Michael A.; IRELAND, R. Duane; HOSKISSON, Robert E. Administração Estratégica: Competitividade e Globalização. 2. Ed. São Paulo: Centage Learning, 2008. 
LIMA, Maria José de Oliveira. As empresas familiares da cidade de Franca: Um estudo sob a visão do serviço social. São Paulo: cultura acadêmica, 2009.

LUDWING, Antonio Carlos Will. Fundamentos e Prática de Metodologia Científica. 2 ed. Petrópolis, RJ: Vozes, 2012.

MELO NETO, F. P. de; FROES, C. Gestão da Responsabilidade Social Corporativa: O Caso Brasileiro. Rio de Janeiro: Qualitymark, 2001.

NASCIMENTO, Luis Felipe; LEMOS, Ângela Denise Da Cunha; MELLO, Maria Celina Abreu de. Gestão Socioambiental Estratégica. Porto Alegre: Bookman, 2008.

SCHOLL, C. A.; HOURNEAUX JR. F.; GALLELI, B. Sustentabilidade organizacional: aplicação de índice composto em uma empresa do setor químico. Gest. Prod., São Carlos, v. 22, n. 4, p. 695-710, 2015. Disponível em: <http://www.scielo.br/pdf/gp/v22n4/0104-530X-gp0104-530X1343-13.pdf>. Acesso em: 14 nov.2016.

TACHIZAWA, Takeshy. Gestão Ambiental e Responsabilidade Social Corporativa. 3 ed. Revista e ampliada. São Paulo: Atlas, 2005.

VALLE, Cyro Eyer do. Qualidade Ambiental: ISO 14000. $5^{\text {a }}$ ed. São Paulo: Editora SENAC São Paulo, 2004.

WRIGHT, Peter; KROLL, Mark J.; PARNELL, John. Administração Estratégica: Conceitos. São Paulo: Atlas, 2011.

ZARPELON, Márcio Ivanor. Gestão e Responsabilidade Social: NBR 16.001/ SA8000: Implantação e Prática. Rio de Janeiro: Qualitymark, 2006.

Como citar este artigo (Formato ABNT):

GOMES, Josivania Lima; MEDEIROS, Adriana Vigolvino. Sustentabilidade na Estratégia como Vantagem Competitiva para as Organizaçõe. Id on Line Rev.Mult. Psic., 2018, vol.12, n.41, p.449469. ISSN: 1981-1179.

Recebido: $27 / 06 / 2018$

Aceito 29/06/2018 